\title{
Desempenho de cultivares de tomateiro em sistema orgânico sob cultivo protegido
}

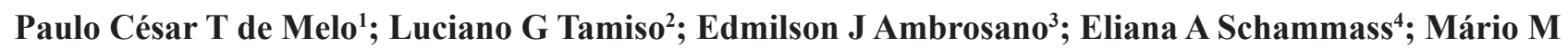 \\ Inomoto $^{1}$; Marcos EM Sasaki ${ }^{5}$; Fabricio Rossi ${ }^{6}$ \\ ${ }^{1}$ USP-ESALQ, C. Postal 9, Piracicaba-SP; ${ }^{2}$ Tamiso Alimentos Orgânicos, Vargem Grande Paulista-SP; ${ }^{3}$ APTA-Polo Centro Sul, Pi- \\ racicaba-SP; ${ }^{4}$ Instituto de Zootecnia, Nova Odessa-SP; ${ }^{5}$ Eng. Agronomo, consultor, Piedade-SP; ${ }^{6}$ Doutor em Fitotecnia, USP-ESALQ, \\ Piracicaba-SP; pctmelo@esalq.usp.br
}

\section{RESUMO}

A agricultura orgânica no Brasil cresce a taxas superiores a $30 \%$ ao ano, devido principalmente à maior conscientização dos consumidores que buscam alimentos saudáveis, livres de resíduos químicos e biológicos. Dentre as hortaliças cultivadas em sistema orgânico, o tomate constitui grande desafio para os produtores devido à inexistência de recomendações de manejo cultural e de cultivares desenvolvidas específicas para esse sistema de cultivo. Diante disso, o presente trabalho teve como objetivo avaliar o desempenho de cultivares de tomate sob sistema orgânico, em ambiente protegido. $\mathrm{O}$ experimento foi conduzido de maio a outubro de 2004 em campo, no município de Araraquara-SP. O delineamento experimental adotado foi blocos ao acaso, com quatro repetições e oito tratamentos (cultivares Avalon, Colibri, HTX-5415, HTX-8027, Sahel, San Marzano, San Vito e Jane). As plantas foram conduzidas em fileiras duplas, com duas hastes por planta no espaçamento de $0,8 \mathrm{~m}$ entre linhas e $0,6 \mathrm{~m}$ entre plantas (cerca de 20.000 plantas ha $^{-1}$ ), sem poda apical. O híbrido Sahel destacou-se com o melhor desempenho para rendimento comercial. A traça-do-tomateiro se revelou como fator limitante à produção de tomate em sistema orgânico, sendo responsável, em média, por $17 \%$ de danos nos frutos colhidos das oito cultivares que foram avaliadas.

Palavras-chave: Solanum lycopersicon L., agricultura orgânica, manejo orgânico, agroecossistemas.

\begin{abstract}
Performance of organically grown tomato cultivars under greenhouse conditions

Organic agriculture in Brazil has been increasing about 30\% per year over the last few years, since consumers are seeking for healthier foods, i.e. nutritious and free of pesticide residues. Among organically grown vegetable crops, tomato is an attractive economic opportunity for growers. However, the lack of information about management practices and adapted cultivars to organic production systems under protected cultivation are pointed out as important constraints that prevents this activity to expand. This work aimed at evaluating the performance of indeterminate tomato cultivars in organic management systems in unheated plastic greenhouse. In both experiments tomato plants were staked. Plant spacing was 1.5 $\mathrm{m}$ between rows and $0.35 \mathrm{~m}$ between plants. They were planted in double line and spaced $0.8 \mathrm{~m}$ between lines and $0.6 \mathrm{~m}$ between plants (about 20,000 plants ha ${ }^{-1}$ ). The experiment was set up in a randomized complete block design, with four replications and eight treatments (cultivars: Avalon, Colibri, HTX-5415, HTX-8027, Sahel, San Marzano, San Vito, and Jane). Sahel hybrid exhibited an outstanding performance for marketable yield under organic cultivation. Tomato pinworm (Tuta absoluta) was a serious limiting pest for organically grown tomatoes, responding for $17 \%$ of damage in the fruits harvested from the evaluated cultivars.
\end{abstract}

Keywords: Solanum lycopersicon L., organic agriculture, organic management, agroecosystems.

\section{(Recebido para publicação em 19 de junho de 2008; aceito em 1 de setembro de 2009)} (Received in June 19, 2008; accepted in September 1, 2009)

\begin{abstract}
$\mathrm{A}$ agricultura orgânica vem ganhando cada vez mais reconhecimento social, político e científico em todo o mundo por estar fundamentada na aplicação de estratégias agroecológicas, mediante o uso de insumos locais, aumentando o valor agregado e propiciando uma cadeia de comercialização mais justa.

$\mathrm{O}$ crescimento do mercado de produtos orgânicos tem o seu alicerce na maior conscientização dos consumidores que demandam alimentos saudáveis e seguros quanto à ausência de resíduos químicos e microbiológicos. Além disso, a sociedade vem se preocupando com os danos causados ao ambiente pelo
\end{abstract}

uso abusivo de agrotóxicos na produção de alimentos.

Para o setor produtivo, o maior atrativo da produção orgânica, inicialmente, está relacionado aos preços mais elevados alcançados no mercado, em comparação ao produto similar produzido por via convencional. No entanto, há também produtores que se interessam por esse sistema devido à possibilidade de diminuição de custos com insumos, pela conscientização da redução de impactos ambientais e melhor funcionamento dos agroecossistemas (Diver et al., 1999).

A agricultura orgânica, no Brasil, é definida pela lei $\mathrm{n}^{\circ} 10.831$ de 23 de dezembro de 2003, do Ministério da Agricultura, Pecuária e Abastecimento (Brasil, 2003), regulamentada pelo decreto $\mathrm{n}^{\circ} 6.323$, de 27 de dezembro de 2007. Esse marco regulatório abrange os sistemas denominados ecológico, biodinâmico, natural, sustentável, regenerativo, biológico, agroecológico e permacultura.

No Brasil, a participação das oleráceas no mercado de orgânicos é ainda incipiente, representando apenas $1,1 \%$ da área total cultivada (Ormond et al., 2002). O levantamento estatístico das culturas realizado sistematicamente pelo 
IBGE não contempla nenhum produto cultivado sob sistema de produção orgânico.

Dentre as hortaliças cultivadas em sistema orgânico no país, o tomate constitui excelente oportunidade de negócio e grande desafio para os produtores. Atualmente, são escassas as informações relativas a cultivares de tomate de mesa adaptadas ao cultivo orgânico, bem como acerca de técnicas de manejo cultural e de controle de pragas e doenças. O tomate, sob sistemas convencionais de produção, é cultivado em diferentes regiões do Brasil e em épocas distintas. A produção no biênio 2006/2007 foi estimada em aproximadamente 3,2 milhões de toneladas, ocupando uma área de cerca de $56 \mathrm{mil}$ hectares (IBGE, 2007).

No processo de seleção de cultivares de tomate, amplitude de adaptação, potencial produtivo, resistência ou tolerância a doenças e pragas, e características organolépticas superiores são os atributos que definem a viabilidade ou não de seu cultivo em escala comercial.

Na concepção de Primavesi (2001), as cultivares devem ter características apropriadas aos sistemas agroecológicos de cultivo. Por conseguinte, cultivares que demandam o uso intensivo de insumos para expressar seu potencial produtivo, como os híbridos, não se adaptariam a tais sistemas. No entanto, resultados obtidos por Bettiol et al. (2004) ao compararem o desempenho produtivo da cultivar de tomate Santa Clara, de polinização livre (PL), com o híbrido Débora, ambos do mesmo segmento varietal, nos sistemas orgânico e convencional em condições de campo aberto, vão em contrário a esta teoria. Em ambos os sistemas de cultivos, 'Débora' mostrou nítida superioridade, em termos de produção comercial, em relação à 'Santa Clara'.

No sistema orgânico, a produção comercial de 'Débora' foi $63,3 \%$ superior à da 'Santa Clara'.

Os problemas fitossanitários constituem o fator limitante principal à expansão da produção de tomate orgânico. Por isso, o uso de cultivares tolerantes ou resistentes pode representar para os produtores uma real vantagem no ma- nejo de pragas e doenças (Diver et al., 1999; Bettiol et al., 2004).

O presente trabalho teve por objetivo estudar o desempenho de cultivares de tomate de polinização livre e híbridas, de porte indeterminado, quanto aos componentes de produção, ataque de pragas e qualidade dos frutos, sob sistema de cultivo orgânico em ambiente protegido.

\section{MATERIAL E MÉTODOS}

O experimento foi conduzido de maio a outubro de 2004, no Sítio Oyafuso, município de Araraquara-SP. O clima da região, segundo Köeppen, é classificado como tropical de altitude, Cwa, com clima quente e inverno seco, no qual a temperatura média do mês mais frio é inferior a $18^{\circ} \mathrm{C}$ e a do mês mais quente ultrapassa $22^{\circ} \mathrm{C}$. O total das chuvas do mês mais seco não atinge 30 $\mathrm{mm}$, e o do mês mais chuvoso é cerca de dez vezes maior do que o do mês mais seco.

A caracterização química do solo da área foi realizada pelo Instituto Agronômico de Campinas, revelando: $\mathrm{MO}=$ $18 \mathrm{~g} \mathrm{dm}^{-3} ; \mathrm{pH}\left(\mathrm{CaCl}_{2}\right)=6,8 ; \mathrm{P}=474 \mathrm{mg}$ $\mathrm{dm}^{-3} ; \mathrm{K}=2,0 \mathrm{mmol}_{\mathrm{c}} \mathrm{dm}^{-3} ; \mathrm{Ca}=69 \mathrm{mmol}$ $\mathrm{dm}^{-3} ; \mathrm{Mg}=25 \mathrm{mmol}_{\mathrm{c}} \mathrm{dm}^{-3} ; \mathrm{H}+\mathrm{Al}=13$ mmol dm ${ }^{-3}$; CTC $=109,3 \mathrm{mmol} \mathrm{dm}^{-3}$; $\mathrm{V}=88 \% ; \mathrm{S}=0 \mathrm{mg} \mathrm{dm}^{-3} ; \mathrm{B}=1,02 \mathrm{mg}$ $\mathrm{dm}^{-3} ; \mathrm{Cu}=8,4 \mathrm{mg} \mathrm{dm}^{-3} ; \mathrm{Fe}=26 \mathrm{mg} \mathrm{dm}^{-3}$; $\mathrm{Mn}=14 \mathrm{mg} \mathrm{dm}^{-3} ; \mathrm{Zn}=10,9 \mathrm{mg} \mathrm{dm}^{-3}$.

$\mathrm{O}$ experimento foi instalado em casa-de-vegetação tipo arco de estrutura de madeira e suas laterais abertas, com dimensões de $7 \times 35 \mathrm{~m}$ e pé direito de $3 \mathrm{~m}$. A cobertura da estufa constituiu-se de filme plástico de polietileno transparente de baixa densidade (PEBD), com espessura de $75 \mu \mathrm{m}$.

O manejo cultural do experimento não diferiu do adotado pelo produtor que desde 1992 cultiva tomate em sistema orgânico e é certificado pela Associação de Certificação Instituto Biodinâmico (IBD).

$\mathrm{Na}$ operação de preparo de solo da área experimental, as plantas de tomate da cultura anterior, juntamente com as plantas espontâneas que nasceram ao longo do cultivo, foram tombadas e trituradas com auxílio de uma roçadeira.
Posteriormente, fez-se a incorporação da massa vegetal com enxada rotativa regulada para operar em baixa rotação, levando-se em consideração o ponto ideal de umidade para o preparo de solo. Em seguida, foi feita aplicação de $200 \mathrm{~g} \mathrm{~m}^{-2}$ de composto orgânico à base de torta de mamona (70\%), farelo de arroz (12,5\%), farinha de conchas $(12,5 \%)$, farinha de peixe $(5 \%)$, capim napier triturado (proporção de 1:1 em relação aos componentes anteriores), 2 L de melaço para 100 L de água e adição de sulfato de zinco (300 g) e ácido bórico (100 g).

O composto foi incorporado superficialmente ao solo, no dia seguinte ao seu preparo, mediante a regulagem do implemento para uma profundidade máxima de incorporação de $10,0 \mathrm{~cm}$. Os canteiros, depois da segunda incorporação, foram cobertos com uma camada de braquiária. Com a palhada disposta na superfície dos canteiros, procedeu-se à instalação do sistema de irrigação.

As mudas foram produzidas em bandejas de polietileno expandido e o substrato orgânico empregado foi confeccionado pelo próprio produtor. O transplantio das mudas foi realizado 34 dias após o semeio.

Utilizou-se irrigação por gotejamento, de acordo com o seguinte cronograma: um dia antes até o primeiro dia após o transplantio das mudas a irrigação foi por 15 minutos; a cada quatro dias até o $20^{\circ}$ dia, a irrigação foi por $15 \mathrm{minu}-$ tos; a partir do $20^{\circ}$ dia a frequência e o tempo de irrigação foram aumentados de acordo com as exigências das plantas; após o surgimento do primeiro racemo, a freqüência e o tempo das irrigações atingiram valores máximos, sendo feitas diariamente durante 1 a 1,5 h.

Aos 46 dias após o transplantio das mudas foi realizada uma adubação foliar com o biofertilizante Supermagro a $0,3 \%$, preparado pelo próprio produtor.

O delineamento experimental foi em blocos ao acaso com quatro repetições e os tratamentos consistiram de oito cultivares de tomate de mesa com hábito de crescimento indeterminado, sendo duas de polinização livre (PL) ('HTX-5415' e 'San Marzano') e as outras seis híbridas 
(cultivares: Avalon, Colibri, HTX-8027, Sahel, San Vito e Jane). A descrição dos materiais avaliados encontra-se no Quadro 1.

A cultivar híbrida Jane foi adotada como referência, por ser produzida em escala comercial sob sistema orgânico na área onde o experimento foi instalado.

A parcela foi constituída por um canteiro com área total de $5,4 \mathrm{~m}^{2}$, com 12 plantas dispostas em fileiras duplas (seis plantas de cada lado), no espaçamento de $0,80 \mathrm{~m}$ entre plantas e $0,60 \mathrm{~m}$ entre plantas na mesma fileira, correspondendo a uma população de 20.000 plantas por hectare.

As plantas foram conduzidas pelo sistema de haste dupla sem poda apical. Adotou-se como parcela útil, oito plan- tas de cada unidade experimental.

Para o controle de pragas foram adotados métodos alternativos. No controle da traça-do-tomateiro (TT) [Tuta $a b$ soluta (Meyrick)] foi adotado controle biológico com a liberação de ovos de Trichogramma spp., sendo colocadas cartelas com 40 mil ovos do parasitóide. A broca-pequena-do-fruto (BPF) [Neoleucinodes elegantalis (Guenée)] e a broca-grande-do-fruto (BGF) [Helicoverpa zea (Boddie)] foram controladas pela pulverização com Bacillus thuringiensis var. kurstaki, linhagem HD-1 (DiPel $\left.{ }^{\circledR} \mathrm{PM}\right)$. No preparo da calda, foram utilizados $100 \mathrm{~g}$ do produto em 100 L de água e aplicados $600 \mathrm{~L}$ de calda/ha. As pulverizações foram realizadas pela manhã ou ao final da tarde.

As aplicações foram feitas na fase de maior atividade larval, determinado pela contagem ou levantamento de pragas, ao se detectar o início das infestações na cultura. Para o controle do ácaro-do-bronzeamento ou microácaro (AB) [Aculops lycopersici (Massee)] foi realizada a aplicação de produto à base de enxofre (Kumulus ${ }^{\circledR}$ ) a 0,3\%.

Foram adotadas medidas de controle para doenças, especificamente para a requeima [Phytophthora infestans (de Bary)], realizada com pulverizações de calda bordalesa (mistura de cal hidratada a $0,3 \%$ e sulfato de cobre a $0,2 \%$ ).

Foram realizadas seis colheitas. Os componentes da produção analisados foram: produção total de frutos (PTF), que representa a massa média de frutos por planta nas diferentes etapas de colheita; produção de frutos comer-

Quadro 1. Descrição das cultivares de tomate de mesa de porte indeterminado incluídas no experimento conduzido em casa-de-vegetação no Sítio Oyafuso (indeterminate fresh tomato cultivars evaluated in the experiment conducted in greenhouse at Oyafuso Farm). Araraquara, ESALQ, 2004.

\begin{tabular}{|c|c|c|}
\hline Cultivares & Descrição varietal & Resistência a doenças \\
\hline Avalon & $\begin{array}{l}\text { Híbrido } F_{1} \text { do grupo Santa Clara desenvolvida pela empresa Hortivale } \\
\text { Sementes do Vale Ltda.; produz fruto firme, grande }(170-200 \mathrm{~g}) \text {, trilocular, } \\
\text { ombro de cor uniforme e boa conservação pós-colheita (longa vida estrutural); }\end{array}$ & V1, Fol 1-2, Tm \\
\hline Colibri & $\begin{array}{l}\text { Híbrido } \mathrm{F}_{1} \text { com planta vigorosa, com ampla capacidade de adaptação, in- } \\
\text { clusive sob temperatura elevada; possui fruto trilocular com formato inter- } \\
\text { mediário entre o tipo Santa Cruz e o Saladete; tem boa firmeza e peso médio } \\
\text { variando de } 180 \text { a } 200 \mathrm{~g} \text {. É comercializado pela Clause-Tezier do Brasil; }\end{array}$ & Tm, Fol 1-2, V1, St, N \\
\hline HTX-5415 & $\begin{array}{l}\text { Cultivar de polinização livre (PL), tipo Saladete, com frutos de alta firmeza } \\
\text { (longa vida estrutural), trioculares e cicatriz peduncular mediana; }\end{array}$ & V1, Fol 1-2, N \\
\hline HTX-8027 & $\begin{array}{l}\text { Híbrido experimental da Hortivale Sementes do Vale Ltda.; pertence ao } \\
\text { segmento Santa Cruz, possuindo planta vigorosa e frutos predominantemente } \\
\text { triloculares, de elevada firmeza (longa vida estrutural) e cor dos ombros } \\
\text { uniforme; }\end{array}$ & V1, Fol-1, N \\
\hline Sahel & $\begin{array}{l}\text { Híbrido } \mathrm{F}_{1} \text { da Rogers Seeds/Syngenta Seeds, do tipo saladete, com alto po- } \\
\text { tencial produtivo e muito uniforme. Possui frutos grandes, com 3-4 lóculos, } \\
\text { alongados e muito firmes; }\end{array}$ & V1, Fol 1-2, Fr, St, Tm, N \\
\hline San Marzano & $\begin{array}{l}\text { Cultivar comum (PL) de origem italiana com plantas vigorosas e frutos tipi- } \\
\text { camente alongados, biloculares, de baixa consistência e ocos. Destaca-se pelo } \\
\text { excelente sabor. A colheita se inicia de } 100 \text { a } 110 \text { dias após a semeadura; }\end{array}$ & \\
\hline San Vito & $\begin{array}{l}\text { Híbrido } \mathrm{F}_{1} \text { do tipo italiano desenvolvido pela Embrapa Hortaliças; apresenta } \\
\text { alto pegamento de frutos. Os frutos são firmes, biloculares e formato alon- } \\
\text { gado. A colheita se inicia } 80 \text { dias após o transplante; }\end{array}$ & $\begin{array}{l}\text { Bsp, St, Fol 1-2, V1, N; } \\
\text { pulgão das solanáceas }\end{array}$ \\
\hline Jane & $\begin{array}{l}\text { Híbrido } \mathrm{F}_{1} \text { com alto potencial produtivo; fruto com peso médio de } 290 \mathrm{~g} \text {, } \\
\text { multilocular do tipo salada longa vida, firmeza média; comercializado pela } \\
\text { Sementes Sakama Ltda.. }\end{array}$ & Tm, V1, Fol 1-2, Sw \\
\hline
\end{tabular}


ciais $(\mathrm{PCF})$, que corresponde à massa média dos frutos classificados dentro dos padrões comerciais nas diferentes colheitas; quantidade total de frutos (QTF), obtido pela média por planta de todos os frutos colhidos nas diferentes datas; quantidade comercial de frutos (QCF), obtido pela média por planta de todos os frutos classificados dentro dos padrões comerciais; massa média de frutos comerciais (MFC), que constitui a relação entre PCF e QCF.

O critério de classificação comercial dos frutos (CCF) se baseou nas Normas de Classificação estabelecidas pelo Centro de Qualidade em Horticultura/ Ceagesp, pertencente ao Programa Brasileiro para Modernização da Horticultura (CEAGESP, 2003).

Os frutos foram classificados individualmente de acordo com o diâmetro equatorial (em mm). Pelas normas adotadas, foram considerados frutos com padrão comercial aqueles que não exibiram defeitos e que se enquadraram entre as classes 40 e 90.

Os frutos de classes 50 e 60 são os de maior aceitação comercial. Os frutos não comerciais são aqueles que se enquadraram nas classes 0 e 100 e que mostraram algum tipo de defeito.

Com relação a características de qualidade do fruto foram avaliados firmeza e tamanho da cicatriz peduncular. A firmeza do fruto (FF) foi avaliada de forma subjetiva pressionando-se manualmente os frutos maduros e o índice de consistência foi obtido com escala de notas, cujos valores variaram de 1,0 (fruto muito mole) a 5,0 (fruto muito firme).

A determinação da firmeza por método subjetivo tem se mostrado altamente correlacionado com a medição feita por métodos não-destrutivos, em que são utilizados instrumentos apropriados para avaliar essa característica (Macnish et al., 1997).

Pelo critério adotado de avaliação do tamanho da cicatriz peduncular (CP) foi considerada pequena (P) uma cicatriz com diâmetro de 3,0 a 4,0 mm, média (M), entre 4,1 a 5,0 mm, grande (G), entre 5,1 a 10,0 mm e extra-grande (XG), entre 10,1 a 14,0 mm.

A ocorrência de pragas foi avaliada no momento da classificação dos frutos, tendo sido calculada a porcentagem de frutos que exibiam danos característicos causados pelas pragas TT, BPF, BGF e percevejo sugador do tomate (PST) [Phthia picta (Drury)].

A incidência de nematóides foi avaliada após a última colheita do experimento. Inicialmente, foi feita uma observação geral do sistema radicular das plantas em cada parcela, com o objetivo de verificar se havia homogeneidade de incidência do patógeno dentro das parcelas. Foram, então, retiradas três amostras de cada tratamento, as quais foram avaliadas visualmente utilizando-se escala de notas oscilando de 0 a $100 \%$, sendo o valor $0 \%$ para o tratamento cujas raízes não apresentavam nenhuma galha e o valor $100 \%$ para o que apresentava o sistema radicular totalmente infestado. Amostras de raízes foram também enviadas para o Laboratório de Nematologia da USP-ESALQ, visando à identificação das espécies de nematóide predominantes.

Os dados referentes à produção total (PTF) e comercial de frutos por planta (PCF) foram transformados em $\sqrt{x}$. Obtendo-se o valor de $F$ significativo para tratamento, procedeu-se à comparação das médias entre cultivares pelo método de análise de agrupamento univariado proposto por Scott \& Knott (1974), ao nível de 5\%.

\section{RESULTADOS E DISCUSSÃO}

A produtividade do tomateiro é função direta do número de plantas por unidade de área, do número de frutos por planta e do peso médio dos frutos (Streck et al., 1998).

O híbrido Sahel foi o que apresentou melhor desempenho para PTF $(5,8 \mathrm{~kg}$ planta $\left.^{-1}\right)$ e PCF $\left(3,9 \mathrm{~kg}_{\text {planta }}{ }^{-1}\right)$, superando estatisticamente todos os demais tratamentos. Em seguida, destacou-se o híbrido San Vito, com valores de PTF e PCF de 4,6 kg planta ${ }^{-1}$ e 2,6 kg planta-1, respectivamente. $\mathrm{O}$ híbrido Colibri apresentou o menor potencial produtivo, tanto para PTF (2,2 kg planta $\left.{ }^{-1}\right)$ como para PCF $\left(1,2 \mathrm{~kg}\right.$ planta $\left.^{-1}\right)$. Porém, em

Tabela 1. Quantidade total de frutos (QTF), quantidade comercial de frutos (QCF), produção total de frutos (PTF), produção comercial de frutos (PCF), massa média de frutos comerciais (MFC) e firmeza dos frutos (FF) (total fruit number (TFN), commercial fruit quality (CFQ), total fruit yield (TFY), commercial fruit yield (CFY), average commercial fruits mass (ACFM) and fruit firmness (FF)). Araraquara, ESALQ, 2004.

\begin{tabular}{|c|c|c|c|c|c|c|}
\hline \multirow{2}{*}{ Cultivares } & QTF & QCF & PTF & PCF & \multirow{2}{*}{$\begin{array}{c}\text { MFC } \\
\left(\text { g fruto }^{-1}\right)\end{array}$} & \multirow{2}{*}{$\mathrm{FF}^{*}$} \\
\hline & \multicolumn{2}{|c|}{$\left(n^{\circ}\right.$ planta $\left.^{-1}\right)$} & \multicolumn{2}{|c|}{$\left(\right.$ g planta $\left.^{-1}\right)$} & & \\
\hline Avalon & $44,6 \mathrm{c}$ & $17,2 \mathrm{c}$ & $3122,6 \mathrm{c}$ & $1790,9 \mathrm{c}$ & $102,6 \mathrm{~b}$ & 3,0 \\
\hline Colibri F1 & $32,2 \mathrm{~d}$ & $13,0 \mathrm{~d}$ & $2183,5 \mathrm{~d}$ & $1154,3 \mathrm{~d}$ & $96,3 \mathrm{~b}$ & 4,5 \\
\hline HTX-5415 & $49,3 \mathrm{c}$ & $21,4 \mathrm{c}$ & $3457,2 \mathrm{c}$ & $2032,5 \mathrm{c}$ & $94,6 \mathrm{~b}$ & 5,0 \\
\hline HTX-8027 & $55,4 \mathrm{~b}$ & $17,5 \mathrm{c}$ & $3306,9 \mathrm{c}$ & $1492,8 \mathrm{~d}$ & $84,8 \mathrm{c}$ & 5,0 \\
\hline Sahel & 68,9 a & $40,3 \mathrm{a}$ & $5763,7 \mathrm{a}$ & 3856,4 a & $96,8 \mathrm{~b}$ & 3,0 \\
\hline San Marzano & $59,2 \mathrm{~b}$ & $28,7 \mathrm{c}$ & $3086,2 \mathrm{c}$ & $1771,2 \mathrm{c}$ & $63,2 \mathrm{~d}$ & 1,0 \\
\hline San Vito & $68,2 \mathrm{a}$ & $30,7 \mathrm{~b}$ & $4606,3 \mathrm{~b}$ & $2635,4 \mathrm{~b}$ & $87,4 \mathrm{c}$ & 4,5 \\
\hline Jane & $34,8 \mathrm{~d}$ & $17,8 \mathrm{c}$ & $3295,5 \mathrm{c}$ & $2180,7 \mathrm{c}$ & $123,2 \mathrm{a}$ & 2,5 \\
\hline $\mathrm{CV}(\%)$ & 10,9 & 21,6 & 13,1 & 2,6 & 13,8 & \\
\hline
\end{tabular}

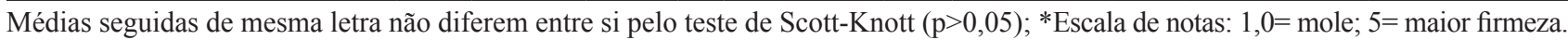


Tabela 2. Danos causados pelas pragas nos frutos de tomate (\%) (damage caused by pests in tomato fruits(\%)). Araraquara, ESALQ, 2004.

\begin{tabular}{lccccc}
\hline \multirow{2}{*}{ Cultivares } & \multicolumn{5}{c}{ Danos nos frutos (\%)* } \\
\cline { 2 - 6 } & BGF & BPF & TT & PST & Total \\
\hline Avalon & 0,6 & 2,8 & 15,9 & 2,0 & 21,4 \\
Colibri F1 & 1,0 & 2,8 & 20,0 & 1,9 & 25,7 \\
HTX-5415 & 1,0 & 4,2 & 21,1 & 0,8 & 27,0 \\
HTX-8027 & 0,8 & 1,8 & 14,7 & 1,0 & 18,3 \\
Sahel & 0,8 & 2,5 & 16,6 & 0,2 & 20,1 \\
San Marzano & 1,6 & 3,4 & 16,5 & 0,8 & 22,4 \\
San Vito & 0,8 & 3,9 & 18,9 & 1,0 & 24,6 \\
Jane & 0,4 & 3,7 & 13,0 & 2,0 & 19,0 \\
\hline Média & 0,09 & 3,14 & 17,09 & 1,21 & 22,3 \\
\hline
\end{tabular}

*BGF = broca-grande-do-fruto; $\mathrm{BPF}=$ broca-pequena-do-fruto; $\mathrm{TT}=$ traça-do-tomateiro $\mathrm{e}$ $\mathrm{PST}=$ percevejo sugador.

relação à PCF não diferiu estatisticamente do híbrido HTX-8027 (1,5 kg planta $\left.^{-1}\right)$. 'Avalon', 'HTX-5415', 'San Marzano' e 'Jane' apresentaram resultados intermediários para essas duas características estudadas.

Os híbridos Sahel e San Vito apresentaram maiores médias para QTF, não diferindo estatisticamente entre si. Entretanto, para QCF, o híbrido Sahel (40,3 frutos planta ${ }^{-1}$ ) superou 'San Vito' (30,7 frutos planta $\left.{ }^{-1}\right)$. Para QTF as médias mais baixas foram observadas para as cultivares Colibri e Jane. Para QCF, as menores médias foram obtidas para os híbridos Colibri (13,0 frutos planta $\left.{ }^{-1}\right)$, Avalon (17,2 frutos planta $\left.{ }^{-1}\right)$, HTX-8027 (17,5 frutos planta $\left.{ }^{-1}\right)$ e Jane (17,8 frutos planta $\left.^{-1}\right)$ que não diferiram estatisticamente entre si. Como observado para PTF e PCF, as cultivares PL HTX-5415 e San Marzano, de novo, apresentaram para QTF e QCF médias superiores que as dos híbridos HTX-8027 e Colibri (Tabela 1).

A maior massa média de fruto comercial (MFC) foi verificada na 'Jane' (123,3 $\left.\mathrm{g} \mathrm{fruto}^{-1}\right)$, fato justificável pela característica varietal, grupo caqui, de frutos pluriloculares e, portanto, de maior calibre. Entre as demais cultivares avaliadas, 'Avalon' (102,6 $\left.\mathrm{g}_{\text {fruto }}{ }^{-1}\right)$, 'Sahel' (96,8 g fruto-1), 'Colibri' (96,3 g fruto $\left.{ }^{-1}\right)$ e 'HTX-5415' (94,6 g fruto $\left.{ }^{-1}\right)$ obtiveram os melhores resultados para MFC, não diferindo estatisticamente entre si. 'San Marzano' demonstrou o resultado menos promissor para essa característica com massa média de 63,2 $\mathrm{g}$ fruto $^{-1}$ (Tabela 1).

Em relação à firmeza do fruto $(\mathrm{FF})$ de cada uma das cultivares avaliadas verificou-se que 'HTX-5415' $(5,0)$, 'HTX-8027' (5,0), 'Colibri' $(4,5)$ e 'San Vito' $(4,5)$ obtiveram as maiores notas para firmeza e que 'Avalon' $(3,0)$, 'Sahel' $(3,0)$ e 'Jane' $(2,5)$ exibiram firmeza média (Tabela 1). Conforme esperado, 'San Marzano' apresentou frutos moles $(1,0)$, de acordo com a descrição do Quadro 1.

A avaliação do tamanho da cicatriz peduncular (CP) revelou que 'San Marzano' possui cicatriz pequena (P), 'Avalon', 'Colibri', 'HTX-5415', 'HTX-8027', 'Sahel' e 'San Vito' têm cicatriz grande $(G)$ e 'Jane', extra grande (XG). A característica CP é um atributo muito importante na definição do padrão de qualidade visual do fruto de tomate. Em geral, cultivares com frutos do tipo caqui, como é o caso de 'Jane', exibem $\mathrm{CP}$ maior do que a das cultivares do tipo Santa Cruz e Italiano, que apresentam, ainda, menor número de lóculos e frutos de menor tamanho.

Em média, $69,30 \%$ dos frutos foram classificados dentro dos padrões de qualidade para comercialização, sendo $31,80 \%$ nas classes 50 e 60 , de maior aceitação comercial (Tabela 1). Os híbridos 'Sahel' e 'Jane' apresentaram a maior porcentagem de frutos comerciais $(82 \%)$. Por outro lado, a cultivar San Marzano apresentou a maior porcentagem de frutos considerados não comerciais (54\%). Valores significativos de frutos não comerciais, também foram observados nas cultivares HTX-5415, HTX-8027 e San Vito, com mais de $30 \%$ de frutos não alcançando padrão de comercialização. As cultivares de polinização livre, em geral, obtiveram, em média, maior porcentagem de refugos $(43,5 \%)$ em comparação às cultivares híbridas (26,5\%) (Tabela 1).

As principais pragas que ocorreram no período de condução do ensaio foram traça-do-tomateiro (TT), broca-pequenado-fruto (BPF), broca-grande-do-fruto (BGF) e e percevejo sugador do tomate (PST). Não foi realizado o levantamento do nível populacional de cada praga. Entretanto, a Tabela 2 mostra o nível de dano causado por cada praga, cuja anotação foi realizada durante a etapa de classificação dos frutos colhidos. $\mathrm{O}$ ataque total de pragas nos oito tratamentos variou de $18,3 \%$, no híbrido HTX8027, a 27\% na cultivar PL HTX-5415, sendo a média de $22,3 \%$ (Tabela 2). A TT foi a praga mais limitante, com nível médio de dano de $17 \%$. A cultivar de polinização aberta HTX-5415 (21,1\%) e o híbrido Colibri $(20,0 \%)$ apresentaram as maiores porcentagens de frutos atacados pela TT, enquanto os híbridos HTX-8027 e Jane, ambas com 15\% de frutos danificados, foram as cultivares menos afetadas por essa praga (Tabela 2). Esses resultados não confirmam aqueles reportados por Medeiros et al. (2006), que verificaram não-preferência da TT por parcelas de tomate sob cultivo em sistema orgânico. Levando em conta os resultados obtidos, ficou evidente que a infestação de pragas é responsável, isoladamente, por quase um quarto dos danos registrados nos frutos. O nível de danos verificado nas condições em que o experimento foi conduzido, em ambiente protegido, e com a aplicação de produtos permitidos pelas normas de produção (Brasil, 2003), sugere que o ataque de pragas constitui ainda um grande desafio a ser vencido no sentido de maximizar a produtividade da cultura do tomate sob sistema orgânico. Essa constatação é corroborada por Diver et al. (1999) que consideram a infestação de pragas e a incidência de doenças os grande entraves da produção orgânica de tomate nos Estados Unidos. 
Tabela 3. Nível de infestação e espécies de nematóides do gênero Meloidogyne presentes no sistema radicular de tomateiro (level of infestation and nematode species of the genus Meloidogyne observed at root system of tomato plants). Araraquara, ESALQ, 2004.

\begin{tabular}{lcc}
\hline Cultivares & Nível de infestação (\%) & Espécie do nematóide* \\
\hline Avalon & $20-40$ & $\mathrm{Mi}, \mathrm{Mj}, \mathrm{Ma}$ \\
Colibri F1 & $20-40$ & $\mathrm{Mi}$ \\
HTX-5415 & 0 & - \\
HTX-8027 & $20-40$ & $\mathrm{Mi}, \mathrm{Ma}$ \\
Sahel & $0-10$ & $\mathrm{Mi}$ \\
San Marzano & $60-80$ & $\mathrm{Mi}, \mathrm{Mj}, \mathrm{Ma}$ \\
San Vito & $0-05$ & $\mathrm{Mi}$ \\
Jane & $80-100$ & $\mathrm{Mi}, \mathrm{Mj}$ \\
\hline
\end{tabular}

$* \mathrm{Mi}=$ M. incognita $; \mathrm{Mj}=$ M. javanica $\mathrm{e} \mathrm{Ma}=$ M. arenaria .

O nível de incidência de doenças manteve-se baixo durante todas as fases fenológicas da cultura. As aplicações de calda bordalesa foram eficazes no controle da requeima ( $P$. infestans) cuja incidência foi inexpressiva mesmo no período de declínio de temperaturas entre junho e agosto.

Com relação aos danos causados por nematóides, a avaliação visual realizada revelou que as cultivares San Marzano (60 a $80 \%)$ e Jane (80 a 100\%) apresentaram maiores níveis de infestação por Meloidogyne, espécies incognita, javanica e arenaria. Entre as demais cultivares avaliadas, 'Avalon', 'Colibri' e 'HTX-8027' apresentaram de 20 a 40\% de infestação, e 'HTX-5415' e 'San Vito' comportaram-se como resistentes.

Chama a atenção o fato de que cultivares descritas como resistentes a nematóides, como 'Colibri' (20 a 40\%), 'HTX-8027' (20 a 40\%), 'Sahel (0 a $10 \%)$ ', e 'San Vito' (0 a 5\%), mostraram níveis variáveis de galhas nas raízes (Tabela 3).

Deve-se levar em consideração que o gene $M i$ confere resistência incompleta ou parcial às espécies de Meloidogyne, exceto M. hapla (Laterrot, 1973). Além disso, a resistência conferida por esse gene perde a eficácia sob condições de temperatura acima de $27^{\circ} \mathrm{C}$, quando está em homozigose, ou a $27^{\circ} \mathrm{C}$, quando se encontra em heterozigose (Nunez, 1995). Desse modo, a divergência de comportamento das cultivares 'Sahel', 'San Vito' e 'Colibri' e HTX-8027', portadoras do gene $\mathrm{Mi}$, pode estar relacionada às temperaturas elevadas registradas no ambiente protegido onde o experimento foi conduzido.
O tomateiro é afetado por inúmeras doenças que ocasionam danos tanto ao sistema radicular como à parte aérea da planta, incluindo os frutos, reforçando a importância da utilização, em sistemas de cultivo orgânico, de cultivares com maior amplitude de resistência genética.

Os resultados obtidos no presente estudo, mostram nitidamente que as cultivares de melhor desempenho geral foram os híbridos Sahel e San Vito, ambos portadores de sete genes que conferem resistência genética a doenças limitantes da cultura do tomateiro.

O híbrido Jane resistente ao vírus do mosaico do tomate (ToMV), ao vírus do vira-cabeça do tomateiro (tospovírus), à murcha-de-verticílio (Verticillium dahliae Kleb.) e às raças 1 e 2 da murcha-de-fusário (Fusarium oxysporum f.sp. lycopersici Sacc. Snyder \& Hansen), foi o terceiro melhor classificado, mas não diferiu estatisticamente da cultivar de polinização livre HTX-5415 portadora dos genes Tm, Fol 1-2 e Mi que governam, respectivamente, resistência ao vírus do mosaico do tomate (ToMV), à murcha-de-fusário, raças 1 e 2, F. oxysporum f.sp. lycopersici), (Fol 1-2) e ao nematóides-de-galhas (Meloidogyne spp.).

Resultados semelhantes foram reportados por Bettiol et al. (2004) ao comparar o desempenho produtivo da cultivar (PL) livre Santa Clara com o híbrido Débora em experimento conduzido na região de Campinas-SP. Nesse trabalho, 'Débora' suplantou a cultivar de polinização livre Santa Clara em rendimento comercial tanto no sistema convencional quanto no orgânico. A diferença em favor de 'Débora' foi mais expressiva, no entanto, no sistema orgânico, cuja produção comercial alcançou

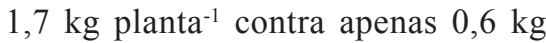
planta $^{-1}$ da cultivar Santa Clara.

É importante ressaltar que, 'Débora' possui resistência à raça 1 da murchade-verticílio $V$. dahliae), à raça 1 de $F$. oxysporum f.sp. lycopersici e a nematóides-de-galhas (Meloidogyne spp.), enquanto a 'Santa Clara' é resistente apenas à raça 1 de $F$. oxysporum f.sp. lycopersici (Nagai, 1985). Portanto, a escolha de cultivares é essencial no cultivo orgânico, uma vez que a resistência genética a doenças pode representar o único método de controle disponível (Bettiol et al., 2004).

A questão cultivar de polinização livre versus híbrido de primeira geração $\left(\mathrm{F}_{1}\right)$ sempre suscitou polêmica no ambiente da agricultura orgânica. No caso específico do tomate, a crença de que cultivares comuns, rústicas e, portanto, menos demandantes de insumos modernos, poderiam mostrar melhor desempenho em manejo orgânico que os híbridos, não se sustentaram neste trabalho. De modo geral, ficou evidente a superioridade dos híbridos frente as cultivares de polinização livre. As vantagens dos híbridos sobre tais cultivares são exaltadas sob diferentes aspectos.

De modo geral, o uso de híbridos $\mathrm{F}_{1}$ de tomate em sistema convencional propicia aumentos potenciais na produção de até $40 \%$, maturação precoce, maior uniformidade e vigor inicial e de desenvolvimento, melhor qualidade, resistência a doenças e capacidade de adaptação mais ampla (Melo et al., 1998). Todavia, o fato de o produtor, onde o presente trabalho foi conduzido e outros localizados em diferentes regiões do Brasil, estejam cultivando híbridos de tomate com resultados satisfatórios, não implica que essas cultivares sejam as mais indicadas para otimizar a tomaticultura orgânica. Portanto, torna-se imprescindível o desenvolvimento de programas de pesquisa especificamente focados na área do melhoramento genético orgânico visando à obtenção de cultivares com características adequadas a esse tipo não convencional de exploração agrícola (IFOAM, 2008).

$\mathrm{Na}$ atualidade, existem poucas culti- 
vares disponíveis no mercado mundial, não só de hortaliças, mas de outros cultivos de importância econômica, oriundas de programas de melhoramento genético orgânico (Lammerts Van Bueren, 2002). É certo que no futuro as entidades certificadoras e regulatórias, inclusive no Brasil, exigirão o uso de cultivares desenvolvidas exclusivamente a partir de programas de melhoramento orgânico para qualquer espécie a ser cultivada em sistema orgânico.

\section{AGRADECIMENTOS}

Os autores agradecem ao produtor orgânico Marcelo Oyafuso pela gentileza em ceder sua propriedade para realização da pesquisa, bem como pela colaboração na execução da mesma.

\section{REFERÊNCIAS}

BETTIOL W; GHINI R; GALVÃO JAH; SILOTO RC. 2004. Organic and conventional tomato cropping systems. Scientia Agricola 61: 253-259.
BRASIL. Lei n. 10.831, de 23 de dezembro de 2003. Diário Oficial da União, 24 dez. 2003. Seção I. Dispõe sobre a agricultura orgânica e outras providências.

CEAGESP - Companhia de entrepostos e armazéns gerais de São Paulo. 2003. Programa brasileiro para a modernização da horticultura: Normas para a classificação do tomate. Centro de Qualidade em Horticultura, São Paulo, 26.

DIVER S; KUEPPER G; BORN H. 1999. Organic tomato production. ATTRA, 25p.

IBGE. 1998. Pesquisa de orçamentos familiares: consumo alimentar domiciliar per capita. Rio de Janeiro, 27p.

IFOAM - International Federation of Organic Agriculture Movements. 2008, 07 de abril. Basic standards for organic production and processing. Disponível em http://www. ifoam.org/

LAMMERTS VAN BUEREN ET. 2002. Organic plant breeding and propagation: concepts and strategies. Netherlands: Wageningen University. 210p. (Thesis).

LATERROT H. Sélection de variétés de tomate resistentes aux Meloidogyne. 1973. European and Mediterranean Plant Protection Organization Organisation 1: 89-92.

MELO PCT; MIRANDA JEC; COSTA CP. 1998. Possibilidades do uso de híbridos $\mathrm{F}_{1}$ de tomate. Horticultura Brasileira 6: 4-6.

MACNISH AJ; JOYCE DC; SHORTER AJ. 1997. A simple non-destructive method for laboratory evaluation of fruit firmness. Australian Journal of Experimental Agriculture 37: 709-713.

MEDEIROS MA; RASI G; SUJII ER; MORAIS HC. 2006. Efeito do sistema de produção de tomate e do consórcio tomate-coentro na flutuação populacional da traça-dotomateiro Tuta absoluta e seus inimigos naturais. In: CONGRESSO BRASILEIRO DE ENTOMOLOGIA, 21, Anais... Recife: SEB (CD-ROM).

NAGAI H. 1985. Santa Clara I-5100, novo cultivar de tomate para mesa. In: CONGRESSO BRASILEIRO DE OLERICULTURA, XXV. Resumos... Horticultura Brasileira 3.

NUNEZ F. 1995. El Cultivo del Tomate. Madrid: Mundi-Prensa. $793 \mathrm{p}$.

ORMOND JGP; PAULA SRL; FAVERET FILHO P; ROCHA LTM. 200205 de maio de 2008. Agricultura Orgânica: quando o passado é futuro. Disponível em: http://www.bndes.gov. br/conhecimento/bnset/set1501.pdf.

PRIMAVESI AM. 2001. Fundamentos da Agroecologia. In: SEMINÁRIO DE AGRICULTURA ORGÂNICA E FAMILIAR, 1. Anais... Campinas: CATI. p. 23-30.

SCOTT AJ; KNOTT MA. 1974. A cluster analysis method for grouping means in the analysis of variance. Biometrics 30: 507-514.

STRECK NA; BURIOL GA; ANDRIOLO JL.1998. Influencia da densidade de plantas e da poda apical drástica na produtividade do tomateiro em estufa de plástico. Pesquisa Agropecuária Brasileira 33: 1105-1112. 